\title{
Learner's satisfaction within a breast imaging eLearning course for radiographers
}

\author{
Inês C. Moreira ${ }^{1,2,3,4}$, Sandra Rua Ventura ${ }^{3}$, Isabel Ramos ${ }^{1,2}$, Pedro Pereira Rodrigues ${ }^{1,5}$ \\ ${ }^{1}$ Faculdade de Medicina da Universidade do Porto, Portugal \\ ${ }^{2}$ Hospital de S. João, EPE, Porto, Portugal \\ ${ }^{3}$ Escola Superior de Tecnologia da Saúde do Porto - Politécnico do Porto, Portugal \\ ${ }^{4}$ Faculdade de Ciências da Universidade do Porto, Porto, Portugal \\ ${ }^{5}$ LIAAD - INESC TEC \& CINTESIS, Porto, Portugal \\ icm@estsp.ipp.pt, sandra.rua@eu.ipp.pt,radiologia.hsj@mail.telepac.pt, \\ pprodrigues@med.up.pt
}

\begin{abstract}
Background: An asynchronous eLearning system was developed for radiographers in order to promote a better knowledge about senology and mammography. Objectives: to assess the learners' satisfaction. Methods: Target population included radiographers and radiography students, in order to assess eLearning satisfaction according to different experience levels in breast imaging. Satisfaction was measured through a questionnaire developed especially for eLearning systems, using a seven-point Likert scale. Main topics related are content, interface, personalization and learning community. Results: Overall, $85 \%$ of learners were satisfied with the course and $87,5 \%$ considered that the course is successful. Main areas that were evaluated by most learners in a positive way were interface and content (between six and seven-point); on the other hand, learning community presented a wider distribution of answers. Conclusions: The course provides an overall high degree of learner satisfaction, thus providing more effective knowledge gain on breast imaging for radiographers.
\end{abstract}

\section{Introduction}

In Europe, breast cancer is responsible for one in every six deaths from cancer in women [1]. Breast cancer related mortality incidence in Portugal reaches 1500 women every year [2]. Thus, early detection and diagnosis of breast cancer is essential to decrease its associated mortality rate; a massive screening is recommended by the medical community [3].
Mammography technique is the imaging examination considered for this screening, representing also a valuable tool for diagnosis, intervention and follow-up of this disease, thus helping on mortality reduction and treatment options increase $[3,4]$. The radiographer has an important role in the performance of mammographic examinations; for this he must be properly prepared and should consequently be subject to specific training and continuing education [5-7]. These issues justify the need of training programs, and in this field eLearning has been revealed to be a useful tool and an alternative to the traditional education method [8].

\subsection{ELearning in healthcare}

There is evidence that continuing education allow to improve the professionals performance, providing better healthcare services $[8,9]$. Several studies [1012] show that radiographers are receptive to new technologies and training, being able to upgrade their skills and extend their role.

The principal advantages of eLearning include the asynchronous ability, cost-savings, personalised learning, increase of accessibility, ease of distribution and update content $[8,12]$. However, time constraints and ease of use are commonly pointed out as drawbacks [9].

With the development of new information technology, several software can be used to implement eLearning systems, ranging from plain web sites and email to blogs, wiki and discussion forums $[8,12]$. Dedicated Learning Management Systems (LMS) support the planning, organisation and access control 
for a specific learning process [8] and regarding Radiology, there are some LMS technologies that improve collaboration, interactivity, simulation, and self-testing [12]. ELearning is therefore a useful tool to help not only students but also professionals moving towards a vision of lifelong and continuous education $[8,9,12]$.

\subsection{ELearning evaluation}

The potential of eLearning systems may not translate into significant improvements in educational outcomes [13]. This way, eLearning needs to be justified by its effectiveness and relevance [14]. Most of the studies evaluating eLearning processes rely on user's satisfaction and knowledge [13-18]. In eLearning environment, several factors account for users' satisfaction. Those factors can be categorized into six dimensions: student, teacher, course, technology, system design, and environmental dimension [19]. Regarding student's dimension, some authors admitted that there is no evidence that learners learn more from eLearning than traditional learning, but in the other hand they can learn more effectively $[13,14]$, mainly due to technical features like accessibility, navigation and user-friendly interfaces [20]. These appreciations can be measured through eLearner satisfaction, which is believed to influence future usage intention and complaining [19]. In fact, elearners with high levels of satisfaction are expected to have higher levels of reuse information and make less complains [20].

There are many studies in literature concerning user's satisfaction in eLearning systems, and therefore there are several user satisfaction questionnaires; one of the most cited questionnaire for eLearning user's satisfaction with asynchronous eLearning systems [21] considers four dimensions of the eLearner satisfaction measurement: content, learner interface, personalization and learning community. From these, the tool specifies 26 items using a seven-point Likert scale (ranging from "strongly disagree" to "strongly agree"), although the last two questions actually reflect global measures related with overall satisfaction and overall success of the eLearning system. Globally, the questionnaire presented a reliability (Cronbach alpha) of 0.95 [21] and is believed to constitute a complete domain for the eLearner satisfaction measurement [22].

\subsection{Aim}

The aim of this work is to assess the learners' satisfaction within an eLearning course on breast imaging for radiographers.

\section{Methods}

An asynchronous eLearning system was developed for radiographers in order to promote a better knowledge about senology and mammography. Afterwards, the course was intended to be evaluated for its efficacy, effectiveness and satisfaction trough a randomised controlled trial. Hence, only those who were allocated to the intervention group were subject to the satisfaction evaluation of the course, thus being only this group described below.

\subsection{Target population and sample strategy}

The target population in this study were radiographers, working at public health institutions in Porto's metropolitan area who perform breast cancer screening and diagnosis, and radiography students attending the 3 rd and 4 th years of the radiology course at the Superior School of Health Technology of Porto, who already had mammography clinical training.

The sample was hence stratified by "professional status" - students and radiographers, and then being invited to participate in the study and perform the eLearning course, by email, after an individual request.

\subsection{Implementation}

Interaction with participants was done mainly by email. The participants were contacted in order to perform the eLearning course. Private asynchronous access, with username and password, was given for a period of 20 days period to those who accepted to perform the course. Then, a final assessment test was delivered to be answered within 5 days. After that, a satisfaction questionnaire was sent to all elearners.

\subsection{The eLearning course description}

The course was written in Portuguese language and developed in Netbeans ${ }^{\circledR}$ version 8.0, using technologies such as Hypertext Preprocessor (PHP), HyperText Markup Language (HTML), JavaScript, Cascading Style Sheets (CSS) and Extensible Markup Language (XML), and hosted at the server of the Faculty of Medicine of the University of Porto. Website security was guaranteed through an authentication mechanism with username and password.

The instructions for taking the course were available on the website, along with a glossary and it was structured into four modules: breast anatomy and physiology, multidisciplinary approach of breast cancer, breast pathology and technical approach of 
mammography. The contents were based on guidelines proposed by the European Society of Breast Cancer Specialists (EUSOMA) [6].

The contents included text, images, videos and Prezy ${ }^{\circledR}$ presentations and were reviewed by medical doctors. Diagnostic images were collected directly from the Breast Centre of Hospital S. João, Porto, with proper legal authorisation.

Given the asynchronous feature of the course, the learner could monitor his evolution learning through a status bar, allowing a clear notion of self-learning.

At the end of each module, a summary of the main key-points and a self-assessment test of six multiplechoice questions were presented; correct answers were immediately available. For the course approval, a final assessment test was sent by email and was available during five days. After approval, a certificate was given to the learners and it was sent the questionnaire satisfaction.

\subsection{Satisfaction questionnaire}

For our study purpose and considering the inexistence of a questionnaire in Portuguese language, an expert translator carried out the translation of the questionnaire proposed by Wang [21] and delivered through GoogleDocs ${ }^{\circledR}$ form creator. In addition, it was asked if participants had already any eLearning experience before, and if it was related to health area; also an optional open-answer question was left for participants to write comments. Demographic data of the participants was collected at the course's first login such as age, gender, academic qualifications, years of professional experience and actual routine mammography.

\subsection{Statistical Analysis}

Normality was tested with the KolmogorovSmirnov test (total sample) and the Shapiro-Wilk test (for each group), beyond the visual analysis of histograms.

The sample was described by median (Md) and 25 and 75 percentiles (P25; P75).

Homogeneity between the two groups was assessed using the Mann-Whitney $U$ test. Chi-square test or Fisher's exact test were used to examine the association between nominal variables.

We considered a significance level of $5 \%$, and the analysis was carried out in IBM SPSS Statistics ${ }^{\circledR}$ software, version 17.0.

\section{Results}

From this study, 54 individuals were requested to perform the course (20 students and 34 radiographers); $44(81 \%)$ - 13 students and 31 radiographers - agreed to take the course, being $10(19 \%)-3$ radiographers and 7 students - considered "lost to follow-up". Nonetheless, 4 elements (9\%) did not attend the full course, being considered "discontinued intervention" (two $(10 \%)$ students and two (6\%) radiographers). At the end, every participant that concluded the eLearning course answered the satisfaction questionnaire $(n=40)$.

\subsection{Sample description}

Considering demographic variables, within 40 individuals, $11(28 \%)$ students and 29 (73\%) radiographers, $32(80 \%)$ were female.

The median age was 21 years old $(\mathrm{P} 25=21 ; \mathrm{P} 75=22)$ for students, and 31 years old $(27 ; 39)$ for radiographers $(\mathrm{p}<0.001)$. Overall, $4(10 \%)$ were 3 rd year students, $7(18 \%)$ were 4 th year students, $3(8 \%)$ had bachelor degree, 23 (58\%) were graduated and 3 $(8 \%)$ had a master's degree.

In the radiographers group, the median professional experience was 9 years $(4 ; 18) ; 12(41 \%)$ individuals did not perform mammography at all, 12 (41\%) performed less than 30 per week, $2(7 \%)$ performed between 30 and 40 per week and $3(10 \%)$ performed more than 40 per week.

\subsection{Satisfaction assessment}

The total questions and answers of the satisfaction questionnaire can be observed in Table 2 and Figure 1, given that no differences were found between the two groups.

Concerning global measures (Question 25 and Question 26), 85\% were satisfied with the eLearning system and $87,5 \%$ considered that the system is successful (between six and seven-point; Q25: students vs. radiographers, $p=0.835$; Q26: $p=0.698)$.

Concerning content topic (Q1-Q4), most learners agreed (between six and seven-point) that the course provides content that exactly fit their needs (Q1: 70\%), and also stated that the content is useful (Q2: 95\%), sufficient (Q3: 60\%) and up-to-date (Q4: 90\%).

Regarding interface and navigation (Q5-Q15), most learners considered the course easy to use (Q5: 92,5\%), thus being also easy to find the content needed (Q6: $87,5 \%)$. Also, the learners found the course easy to understand (Q7: 97,5\%), considering the system userfriendly (Q8: $100 \%$ ). $95 \%$ of learners identified the 
Table 1: Satisfaction questionnaire results. The results are exposed trough median and percentiles 25 and 75 of the total answers for each question $(n=40)$.

\begin{tabular}{|c|c|c|}
\hline & $\begin{array}{l}\text { Median } \\
\left(\mathbf{P}_{25} ; \mathbf{P}_{75}\right) \\
\end{array}$ & $\begin{array}{c}p \text { value } \\
\text { (students vs. radiographers) }\end{array}$ \\
\hline Q1. The eLearning system provides content that exactly fits your needs. & $6(5 ; 7)$ & 0,676 \\
\hline Q2. The eLearning system provides useful content. & $7(6 ; 7)$ & 0,676 \\
\hline Q3. The eLearning system provides sufficient content. & $6(5 ; 7)$ & 0,185 \\
\hline Q4. The eLearning system provides up-to-date content. & $6(6 ; 7)$ & 0,550 \\
\hline Q5. The eLearning system is easy to use. & $7(7 ; 7)$ & 0,633 \\
\hline Q6. The eLearning system makes it easy for you to find the content you need. & $7(6 ; 7)$ & 0,511 \\
\hline Q7. The content provided by the e-learning system is easy to understand. & $7(6 ; 7)$ & 0,419 \\
\hline Q8. The eLearning system is user-friendly. & $7(7 ; 7)$ & 0,698 \\
\hline Q9. The operation of the e-learning system is stable. & $7(6 ; 7)$ & 0,338 \\
\hline Q10. The eLearning system responds to your requests fast enough. & $7(6 ; 7)$ & 0,338 \\
\hline $\begin{array}{l}\text { Q11. The eLearning system makes it easy for you to evaluate your learning } \\
\text { performance. }\end{array}$ & $6(6 ; 7)$ & 0,550 \\
\hline $\begin{array}{l}\text { Q12. The testing methods provided by the e-learning system are easy to } \\
\text { understand. }\end{array}$ & $7(6 ; 7)$ & 0,473 \\
\hline Q13. The testing methods provided by the e-learning system are fair. & $6(5 ; 7)$ & 0,952 \\
\hline Q14. The eLearning system provides secure testing environments. & $6(5 ; 7)$ & 0,676 \\
\hline Q15. The eLearning system provides testing results promptly. & $7(7 ; 7)$ & 0,858 \\
\hline Q16. The eLearning system enables you to control your learning progress. & $7(6 ; 7)$ & 0,139 \\
\hline Q17. The eLearning system enables you to learn the content you need. & $6(6 ; 7)$ & 0,492 \\
\hline Q18. The eLearning system enables you to choose what you want to learn. & $6(5 ; 7)$ & 0,254 \\
\hline Q19. The eLearning system records your learning progress and performance. & $6(6 ; 7)$ & 0,369 \\
\hline Q20. The eLearning system provides the personalised learning support. & $6(5 ; 7)$ & 0,511 \\
\hline $\begin{array}{l}\text { Q21. The eLearning system makes it easy for you to discuss questions with } \\
\text { your teachers. }\end{array}$ & $5(4 ; 6)$ & 0,229 \\
\hline $\begin{array}{l}\text { Q22. The eLearning system makes it easy for you to discuss questions with } \\
\text { other students. }\end{array}$ & $4(3 ; 6)$ & 0,096 \\
\hline $\begin{array}{l}\text { Q23. The eLearning system makes it easy for you to share what you learn with } \\
\text { the learning community. }\end{array}$ & $5(4 ; 6)$ & 0,064 \\
\hline $\begin{array}{l}\text { Q24. The eLearning system makes it easy for you to access the shared content } \\
\text { from the learning community. }\end{array}$ & $5(4 ; 6)$ & 0,157 \\
\hline Q25. As a whole, you are satisfied with the eLearning system. & $6(6 ; 7)$ & 0,835 \\
\hline Q26. As a whole, the eLearning system is successful. & $6(6 ; 7)$ & 0,698 \\
\hline
\end{tabular}

system as stable (Q9) and 77,5\% stated that the system responds to the requests fast enough (Q10). In respect to the learning performance evaluation, most of learners found it easy (Q11: 85\%) and identified the testing methods as fair (Q13: 70\%), secure (Q14: 70\%) and easy to understand (Q12: 90\%); also, 95\% stated that its results are promptly provided (Q15).

Considering the personalization topic (Q16-Q20), most learners agreed that the course enables the learning progress self-control (Q16: 77,5\%), the content needed (Q17: 87,5\%) and chosen by the learner (Q18: 72,5\%), and also enables the record of the learning progress and performance (Q19: 80\%) of the

learner; $57,5 \%$ of the learners agreed that the course provides personalised learning support (Q20).

Concerning "learning community" issue (Q21-Q24), the distribution of the answers is wider (Figure 1), even though part of the participants agreed that the system is easy to provide discussion questions with the teachers (Q21: 55\%) and with other students (Q22: 45\%); $60 \%$ of the learners found that is easy to share what they learned with the learning community (Q23) and 65\% stated that is easy to access the shared content from the learning community (Q24).

Of the 40 elearners, $4(10 \%)$ had previous eLearning experience, and $2(5 \%)$ performed it in the health area. However, the overall satisfaction did not differ between these participants and those who had no previous experience of eLearning (Q25: $p=0.262$; Q26: $p=0.207$ ). For all other questions only one difference was found in Q11, concerning the easy evaluation of the learning process $(p=0.042)$. 


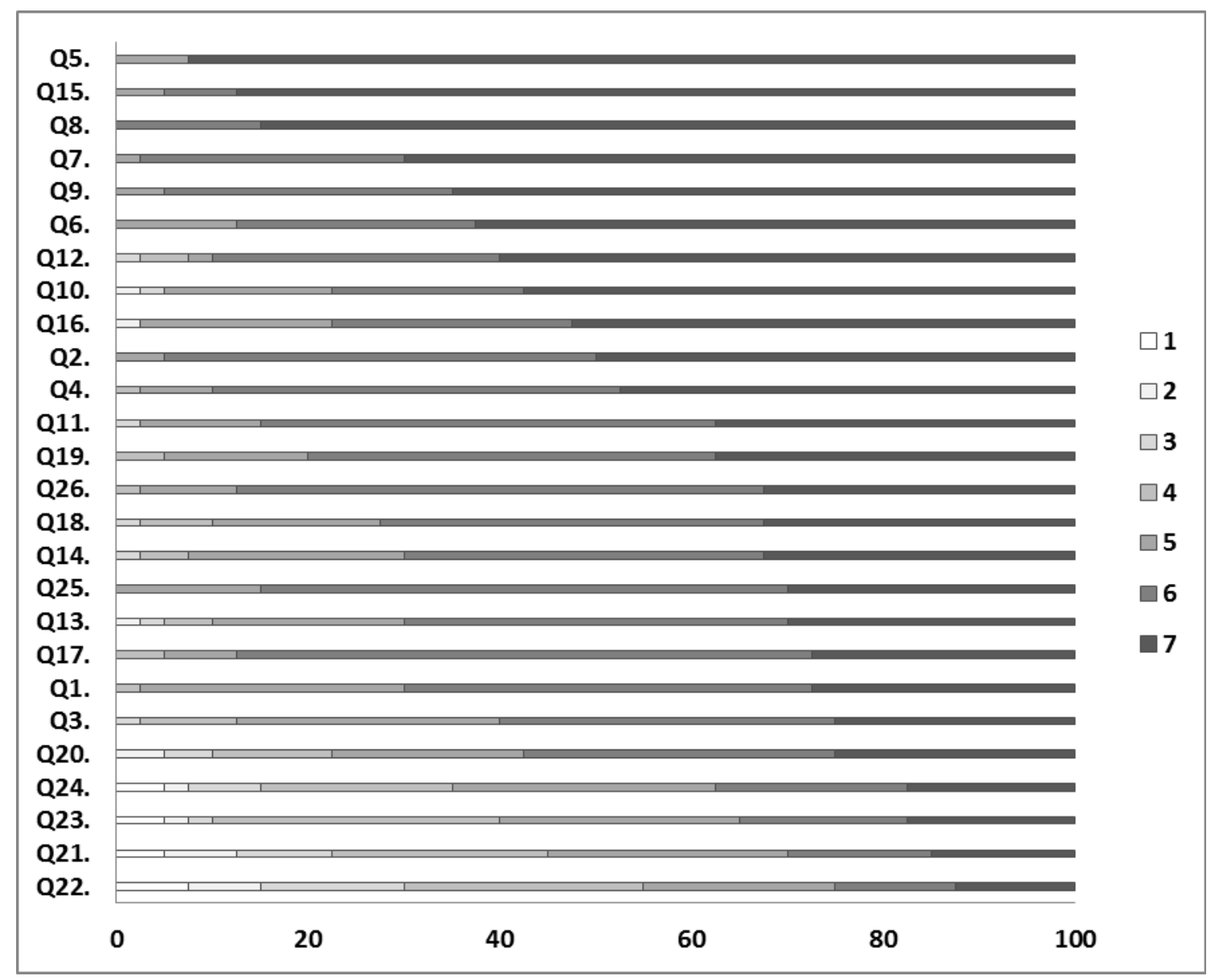

Figure 1: Satisfaction questionnaire results. The graph demonstrates percentages of total answers on each Likert-point. The bars are ordered by the positiveness of response.

\section{Discussion}

Regarding the sample description, no significant differences were encountered between students and radiographers besides age and academic qualifications, as well any significant association between variables.

This study demonstrated that the participants who concluded the eLearning course revealed to be very satisfied with the eLearning system, across the satisfaction questionnaire, regardless being students or radiographers. Regarding comments, learners highlighted the intuitive interface and the useful content as well the necessity of more specific education for radiographers.

Through the analysis of the graphic in Figure 1 we can conclude that the success of the course has been shown mainly at "interface" and "content" topics with a high degree of satisfaction, rather than in the topic of "learning community" which has a lower degree. The construction of the course design consisted of an asynchronous eLearning system, simple and user friendly, not taking into consideration a teacher-student and student-student interaction; hence we can consider the low level of satisfaction in this segment as an expected result. In addition, learners with previous eLearning experience showed lower satisfaction about the evaluation learning performance (Q11); we believe that besides the status bar that was provided for the learner - so he can control the learning process - and the availability of the correct answers after performing the self-assessment tests, there should be other mechanisms that can show to the learner the evolution of knowledge along the course, e.g. the percentage of correct answers given. As future work we intend to improve the course concerning these components.

One limitation of this work is the moderate sample size, so the generalisability of the results is not undeniable. Another restraint was the inexistence of a satisfaction questionnaire for eLearning systems in Portuguese, and therefore we have been obliged to carry out a translation of one of the most cited 
questionnaires in literature. Nevertheless, the validity of this satisfaction evaluation should be carefully discussed, which suggests that a validation of the questionnaire used in this work could be taken as future work, taking advantage of the translation already carried out by the language skilled professional.

We can conclude that the course provides an overall high degree of learner satisfaction, being this type of assessment an important contribution for better eLearning systems thus providing more effective knowledge gain. Furthermore, it would be interesting to perform additional assessments to highlight the association between satisfaction and consolidation of knowledge gain.

\section{Acknowledgments}

This work is supported by the Master Degree in Medical Informatics of the University of Porto (http://mim.med.up.pt).

\section{References}

[1] A. Jemal, F. Bray, et al., "Global Cancer Statistics", Cancer, vol. 61, no. 2, pp. 69-90, 2011.

[2] Liga Portuguesa Contra o Cancro (2009). Liga Portuguesa Contra o Cancro [Online]. Available: http://www.ligacontracancro.pt/gca/index.php?id=42

[3] C. Lee, D. Dershaw, et al., "Breast cancer screening with imaging: recommendations from the Society of Breast Imaging and the ACR on the use of mammography, breast MRI, breast ultrasound, and other technologies for the detection of clinically occult breast cancer", Journal of the $A C R$, vol. 7, no. 1, pp. 18-27, 2010

[4] S. Misra, N. Solomon, et al., "Screening Criteria for Breast Cancer", Advances in Surgery, vol. 44, no 1, pp. 87100, 2010.

[5] N. Perry, M. Broeders, et al., "European guidelines for quality assurance in breast cancer screening and diagnosis", Office for Official Publications of the European Communities, 2006.

[6] L. Cataliotti, C. De Wolf, et al., "Guidelines on the standards for the training of specialised health professionals dealing with breast cancer". European journal of cancer, vol. 43, no. 4, pp. 660-75, 2007.

[7] J. Caseldine, S. Cush, et al., "Quality Assurance Guidelines For Radiographers", in Quality Assurance, publication no 30: Sheffield, 2000.

[8] J. Ruiz, M. Mintzer, et al., "The impact of E-learning in medical education", Journal of the Association of American Medical Colleges, vol. 81 no. 3, pp. 207-12, 2006.

[9] S. Childs S, E. Blenkinsopp, et al., "Effective e-learning for health professionals and students: barriers and their solutions. A systematic review of the literature: findings from the HeXL project", Health information and libraries journal, vol. 22, no. 2, pp. 20-32, 2005.
[10] M. Shanahan, "Radiographers and the internet: an Australian perspective", Radiologic technology, vol. 81, np. 3, pp. 223-32, 2010.

[11] L. Johansen, J. Brodersen, "Reading screening mammograms-attitudes among radiologists and radiographers about skill mix", European journal of radiology, vol. 80, no. 3, pp. 325-30, 2010.

[12] A. Pinto, L. Brunese et al., "E-learning and education in radiology", European journal of radiology, vol. 78, no.3, pp. 368-71, 2011.

[13] H. Chumley-Jones, A. Dobbie, et al., "Web-based learning: sound educational method or hype? A review of the evaluation literature", Journal of the Association of American Medical Colleges, vol. 77, no. 10, pp. 86-93, 2002.

[14] R. Wutoh, S. Boren et al., "eLearning: a review of Internet-based continuing medical education", The Journal of continuing education in the health professions, vol. 24, no. 1 , pp. 20-30, 2004.

[15] G. Alliger, E. Janak, "Kirkpatrick's levels of training criteira: thirty years later", Personnel Psychology, vol. 42, no. 2, pp. 331-42, 1989.

[16] C. Stark, M. Graham-Kiefer, et al., "Online course increases nutrition professionals' knowledge, skills, and selfefficacy in using an ecological approach to prevent childhood obesity", Journal of nutrition education and behavior, vol. 43, no. 5, pp. 316-22, 2011

[17] A. Carriero, L. Bonomo, F. Calliada, et al., "E-learning in radiology: an italian multicentre experience", European Journal of Radiology, vol. 81, no. 12, pp. 3936-3941, 2012.

[18] J. Liu, J. Wyatt, "The case for randomized controlled trials to assess the impact of clinical information systems", $J$ Am Med Inform Assoc, vol. 18, pp. 173-80, 2011.

[19] J. Wu, D. Tennyson, et al., "A study of student satisfaction in a blended e-learning system environment", Computers \& Education, vol. 55, pp. 155-164, 2010.

[20] P. Sun, "What drives a successful e-Learning? An empirical investigation of the critical factors influencing learner satisfaction", Computers \& Education, vol. 50, no. 4, pp. 1183-1202, 2008.

[21] Y. Wang, "Assessment of learner satisfaction with asynchronous electronic learning systems", Information \& Management, vol. 41, pp. 75-86, 2003.

[22] M. Chen, "Influence of dentistry students' e-Learning satisfaction: a questionnaire survey", Journal of medical systems, vol. 35, no.6, pp. 1595-603, 2011. 